\section{EMBRYARIDDLE}

Aeronautical University

SCHOLARLY COMMONS
Journal of Aviation/Aerospace

Education \& Research

Volume 16

Number 1 JAAER Fall 2006

Article 5

Fall 2006

\title{
Models of Aviation Technical Communication with Augmented Reality
}

Anthony Majoros

Dennis Vincenzi

vincenzd@erau.edu

Sathya Gangadharan

sathya@erau.edu

Paul Jackson

Follow this and additional works at: https://commons.erau.edu/jaaer

\section{Scholarly Commons Citation}

Majoros, A., Vincenzi, D., Gangadharan, S., \& Jackson, P. (2006). Models of Aviation Technical Communication with Augmented Reality. Journal of Aviation/Aerospace Education \& Research, 16(1). https://doi.org/10.15394/jaaer.2006.1483

This Article is brought to you for free and open access by the Journals at Scholarly Commons. It has been accepted for inclusion in Journal of Aviation/Aerospace Education \& Research by an authorized administrator of Scholarly Commons. For more information, please contact commons@erau.edu. 


\title{
MODELS OF AVLATION TECHNICAL COMMUNICATION WTTH AUGMENTED REALITY
}

\author{
Anthony Majoros, Dennis Vincenzi, Sathya Gangadharan, and Paul Jackson
}

\begin{abstract}
A fundamental characteristic of augmented reality (AR) is the overlay of computer graphics (e.g., installation instructions) on views of world objects (e.g., a section of an aircraft wing) and registration of those graphics to features in the world scene. In AR, the mechanisms of information retrieval rely on detection of features of real-world objects, and communication is by way of virtual content in a real world scene; causing information to become a function of the composite scene, where real and virtual elements are interdependent. Various models of technical media communication are made possible by these characteristics and are discussed in this paper, including authoring, where a world object reveals what a planner intends it to reveal; image-based dialog, where substrate video is merged with annotations to communicate about world objects; and seamless collaboration, where attributes of in-person communication are replicated in AR. Familiar communication and information processing models are therefore expanded by AR. Communication and cognition aspects of human information processing are discussed in this paper in light of AR capabilities.
\end{abstract}

\section{INTRODUCTION}

Innovative methods of communication are possible with augmented reality (AR), a machine vision and computer graphics technology that merges real and synthetic objects into single, composite scenes. Communication, whether regarded as a transmission process affected by noise (Shannon \& Weaver, 1949) or as a self-modulating process affected by meaning and association (Osgood, 1954) conveys information, and in aerospace, efficiency in technical communication is an unending goal. AR can automatically retrieve and display information in a viewer's visual field: designated parking spots on a view of a flight ramp, repair instructions in a view of a fuel pump, or status information in a view of a payload preparation area. The implication of this capability is that users of information are spared the effort of searching for and formatting information; instead, information that is specific to the visual scenes predicted for users is prepared by specialists, and graphics and computer vision technologies cause the prepared information to appear with no look-up effort by the user.

\section{Direct Vlew AR}

In direct view AR, a user observes the world through a lens or other device that positions instructions or icons in the field of view so that they appear to occupy the same physical space as a viewed object. Figures 1 and 2 (based on Caudell \& Mizell, 1992; Curtis, Mizell, Gruenbaum, \& Janin, 1998) show the effect of direct view AR. In Figure 1, a user views a wire bundle assembly board through a headmounted AR device; Figure 2 presents his view through the device--existing wires laid out on the board are visible and the routing of a new wire (vertical line with change in direction to the right) appears in a transparent graphic superimposed on his view. Most of the experimentation in AR has concerned the direct view approach, such as a study of laser printer maintenance (Feiner, Macintyre, \& Seligmann, 1993), previews of residential construction ( $\underline{w} w \mathbf{w}, c s . c o l u m b$ i a.e d u / graphics/projects/karma/karma.html), and AR in surgical and other medical procedures (www.cs.unc.edu/ us/). 


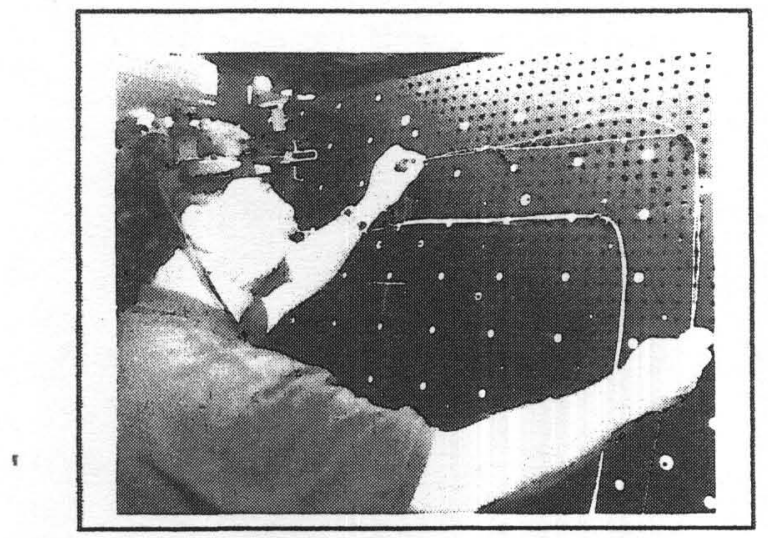

Figure 1. Head-mounted display for direct-view of a wire harness form board augmented with wire layout instructions.

\section{Video-Bused AR}

In video-based AR systems (e.g., Majoros \& Neumann, 2001; Bajura \& Neumann, 1995), a hand-held or headmounted camera view of the world is displayed to the user, a method called "video see-through" or "video-based mixed reality." In this method, highly discernible markers or fiducials are often attached to a real-world object to aid the system in feature detection. Graphics are registered to fiducial locations that are placed in a region of interest captured by a video camera. Figure 3 shows a frame of video where tracking is in relation to three black circular markers affixed to an aircraft passenger window and surrounding structure. Triangular marks appearing to overlay rivet heads around the window are graphics that are geometrically related to the black circular markers. Figure 4 shows a single frame captured from a videorecord of a section of aircraft wing slat assembly where, instead of markers, the system looks for pre-selected natural features (Neumann \& Cho, 1996). On the slat are markings made up of geometric, intersecting bars; aspects of the bars are the features that are tracked across multiple frames of the video; the registered graphics are leader lines and text boxes with letters that remain linked to the circles. Websites with examples of direct view and video-based AR include w w w . a u g m e $\mathrm{t}$ e d - re a l i t y. or g http://www.cs.rit.edu/ jrv/research/ar/ http://www.hitl.washington.edu

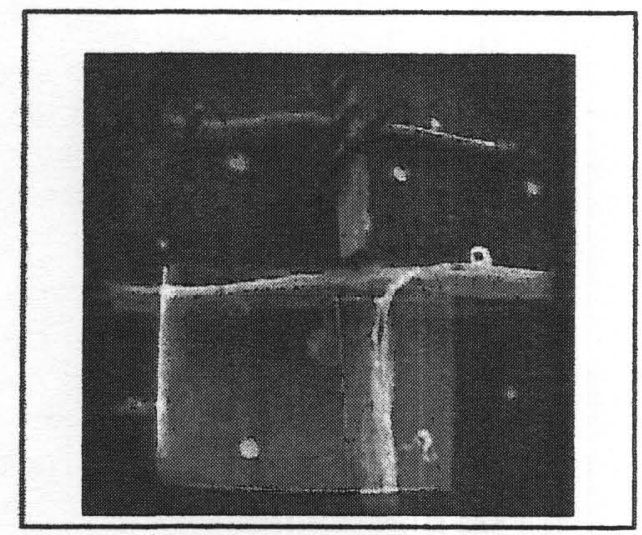

Figure 2. Graphic overlay on direct view of wire harness assembly board. Vertical and horizontal straight lines in the overlay direct the wire layout. 


\section{COMMUNICATION}

Communication is enabled on several levels with AR. These levels include the mechanism whereby a scene or view is authored, or designed according to what someone wants the viewer to observe, and also includes mechanisms where the intent is a reciprocal relationship between parties. "The most basic concept is that a viewer observes a world scene that has been authored; the scene contains the information or links designed earlier in anticipation of a viewer's observation. This concept is similar to preparing a technical instruction manual, where one person creates a document or object that another will view or experience. Authoring

Authoring is the process of designing the appearance of augmented scenes. The author prepares scenes and when a user views a prepared world scene, his or her view reveals what the author intended it to reveal. For the wire harness assembly mentioned earlier, the author's intent is, of course, wire layout instructions. When the communication emphasis is on authoring, the information consumer is somewhat passive, but no more so than with technical media, news, advertising, and many other types of current media. The intent is to provide information, and perhaps a method to navigate information, rather than provide dialog.

Spohrer (1999) envisions a "Worldboard" system as a "new type of communication medium" where individuals and organizations could post information and associate that information with a physical location. The concept in Worldboard is that virtual boards and their content, such as text boxes or marquees, would be registered to places or to positions relative to objects. These boards would primarily operate like message boards or billboards--that is, present information for viewing rather than offer a dialog or other interactive session. Head-mounted, hand-held, or projection devices would then make the information visible at specific geographic or spatial locations. With this system, viewers would observe enhancing information superimposing their normal view of the world; for example, a construction contractor could see the outline of a buried pipe before operating a backhoe, consumers could see "info-mercials" that appeared to occupy space on store windows. In fact, the author argues that a great portion of information has spatial attributes, and is therefore subject to viewing in its spatial context. In aerospace, technologies such as portable or wearable computers have been introduced to make information available at the aircraft; with the Worldboard philosophy, a technician or an inspector would have information appropriate to his or her position in or at the aircraft, and appropriate to a particular aircraft device (e.g., fuel valve or avionics box), and available by viewing aircraft objects with a location-sensitive device.

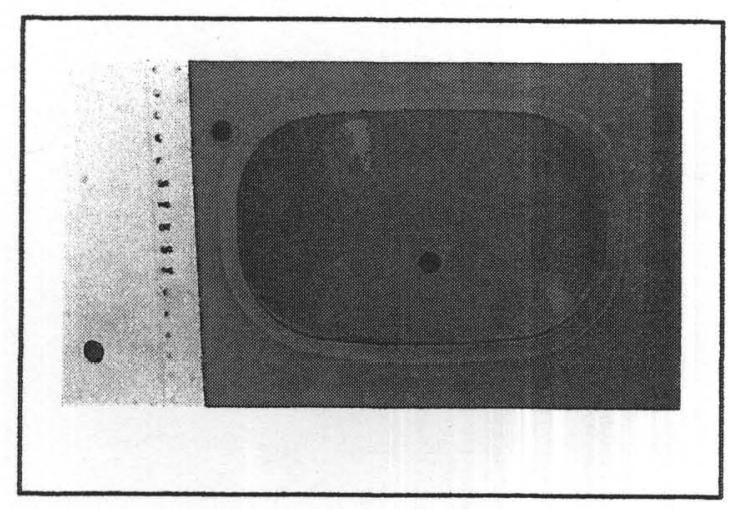

Figure 3. Video-based AR system tracking fiducials: black circular markers are detected and triangular icons at rivet locations are automatically overlaid on the image. 
Computer Supported Collaborative Work

Image-Based Collaboration. With image-based collaboration, direct view or video imagery is merged with annotations to communicate about world objects. The objective in collaboration is multiple input to design or problem-solving.

Direct view real-time systems for collaboration involve graphics superimposed on live images operating in real-time to assist and guide individuals in various types of tasks. $\mathbf{A}$ relatively simple addition of a camera and signal transmission allows a remote assistant to see the same view that the direct view user sees, and to, communicate with him or her via audio transmission. In a more complicated approach, the remote collaborator might also intervene in the real-time overlay of graphics. In either case, the idea is to communicate about a situation where all parties have access to an on-going, embellished video stream enhanced with graphics.

Video-based AR offers a unique opportunity for collaboration. For background, consider a system for engineering collaboration on Space Shuttle modifications in Palmdale, California. With this system (Figure 5), a technician transmits video images to a remote engineering site about 100 miles away, where others can view scenes, mark up selected single frames of imagery, and provide technical information back to the technician without traveling to $\mathrm{Palm}$ dale. With video-based $\mathrm{AR}$, this reciprocal, give-and-take method would be expanded: one party first produces a video record of work pieces to document a problem and conveys the record to a collaborator, the collaborator then annotates the record to provide information about the problem and conveys the annotated version back to the first party. For this method to be quick enough for collaborative sessions, standard video editing will not work; instead, it requires software for feature detection, tracking, and automatic compositing. The collaborator (acting as an author) decides what features in the video should be annotated; software carries the annotations forward automatically and adjusts their positions in relation to features. The advantage and logic with this off-line approach is that time is available (and usually necessary) to study the image and to augment it in a useful way. This image-based collaboration method is consistent with NASA's study of advanced displays in the agency's Aviation Safety Program (Kanki, 2000). Figure 6 shows the effect of tracking across multiple frames. In Figure 7, natural feature tracking supports more elaborate graphics.

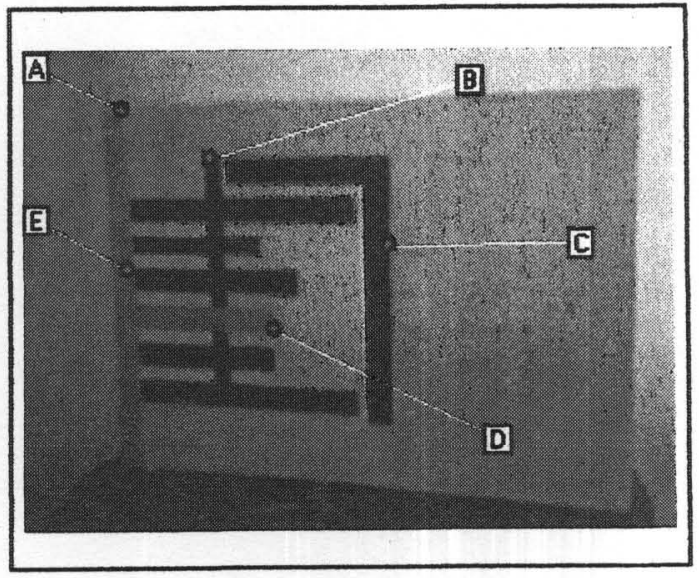

Figure 4. Video-based AR can employ natural feature detection. In this frame of video, text boxes, leader lines, and circular identifiers are all synthetic overlays to the video, and track their assigned features as the slat rotates in the video. 


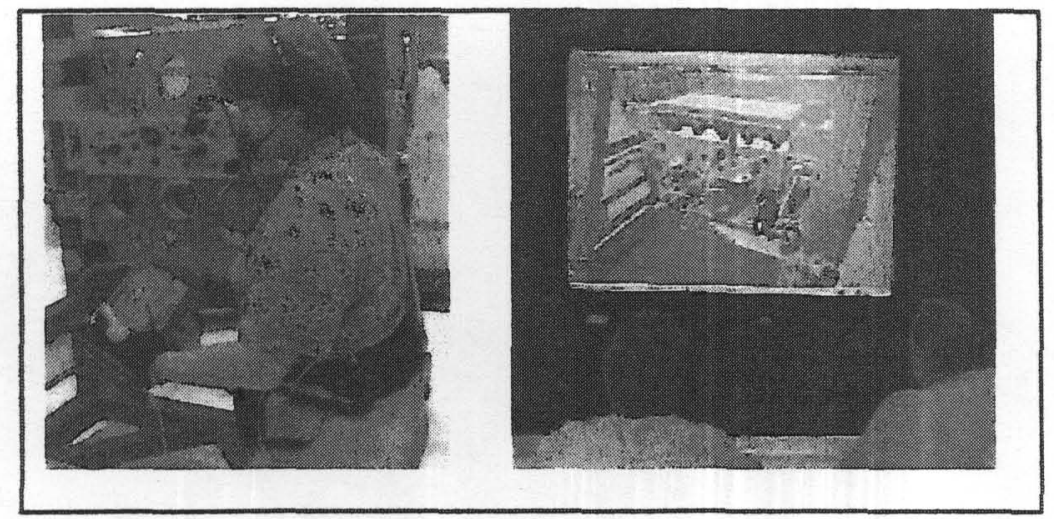

Figure 5. General collaborative engimeering model based on video: image produced at one site is viewed at a remote engimeering location.

This method of dialog is an obvious companion to the markup of still images, a communication technique that is a staple of white board use in NetMeeting. Of course, there are many cases where a still image or a single frame captured from video is a very adequate substrate for notes, questions, arrows to direct attention, or other markups. There are several cases where the markup of motion imagery is an advantage, including the following:

- Interpreting what is happening in a scene of motion imagery

- Clarifying an obscured or ambiguous view

- Communicating the dynamics in a scene, such as simultaneous motion in different directions

- Adding information to a 3D modeled scene; adding information 'gracefully' rather than stopping the motion to show annotations

- Aiding a viewer in tracking a feature in imagery

- Providing multiple views of features in imagery

- Abstracting a rule across multiple views of a feature

- Learning, understanding, and performing complex tasks

- Communicating natural human movements

Rather than facilitating direct interpersonal communication, as CSCW systems are often intended to do, some approaches are aimed at reducing human involvement. Nardi and her co-workers (1997) revealed a video system that reduced the need for interpersonal communication and permitted individuals (neurophysiologists in remote locations) to work independently. The authors conclude, "The video data, plus individual knowledge and understanding, combine to produce an interpretation that leads to the desired collaboration, with little or no interpersonal interaction (p. 499)."

Dialog and Seamless Collaboration. Some AR development is aimed at capturing significant attributes and dynamics of in-person communication. "Seamlessness" is a goal in this area. The term refers to the apparent lack of intervening technology between remotely located persons communicating with one another. For example, a delay in voice transmission indicates a seam or connection of one party's context (the "fabric" in this analogy) to another party's context (more fabric). (In data communications (Grinberg, 1997), seamlessness is a characteristic meaning smooth integration, for example between wired and wireless elements of a system.) In theory, if no seams are apparent, "telepresence" is achieved-a condition where individuals have a sense of occupying a remote location ("being there") or remotely located persons have a sense of being in the same place at the same time. For example, Buxton (1997) created a rear-projection, life-size image of a remote conversant who appeared (because of remote camera placement) to look at his conversational counterpart. Many technologies for telepresence are possible, but in this example, the life-size projection was one attempt to eliminate the seam of unrealistic image size. One reason for technical work toward telepresence is that seams can disrupt 
communication, as when the image and the voice of a speaker are not synchronized. Another reason, at least an implied one, is that for some communication it is better for participants to be in the same location, and if they can't be, then any progress toward eliminating seams will improve communication. It is difficult to find empirical evidence that more telepresence produces improved communications.

Figure 6. With feature tracking, user-selected features are automatieally loeated, tracked, and annotated across multiple frames.
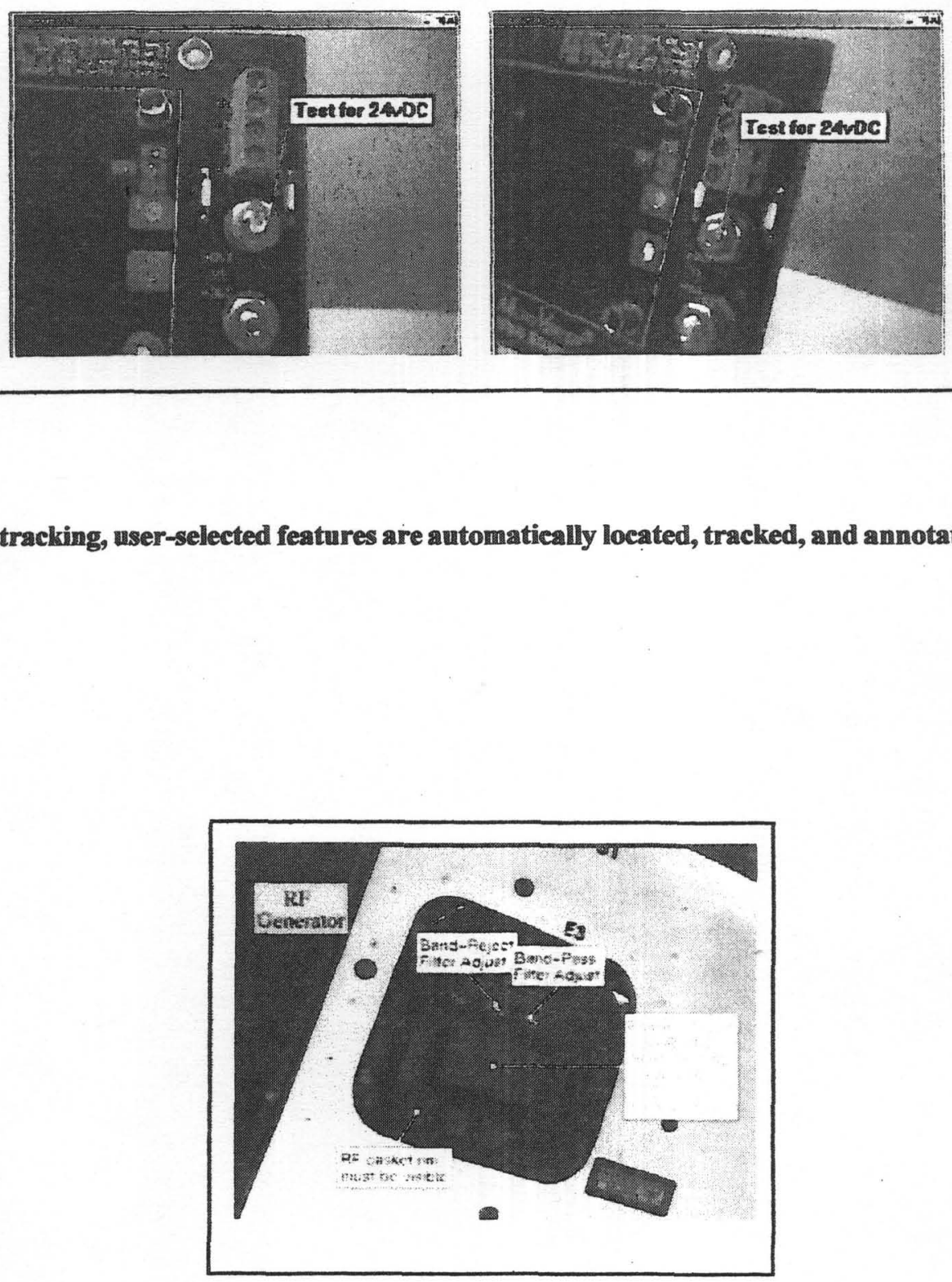

Figure 7. Single frame from video of generator access mockup; graphic overlay is set of text boxes that are automatically registered to natural features across frames in the video. 
It may be simplistic to attempt replicating face-to-face dynamics. Billinghurst and Kato (1999) recommend determining what is needed for dialog across diverse sites and then reducing seams as much as possible in the technology developed for collaboration. For example, with audio-only systems, users cannot tell who else is present and cannot use visual cues to determine other's readiness to interact. Entirely synthetic (virtual reality) collaborative environments also reveal shortcomings, such as the inability to interact with the real world. AR environments for collaboration are seamless in that they involve traditional tools and practices while overlaying virtual images onto the real world.

\section{ISSUES AND CONNECTIONS Importance of Video Imagery}

An issue with video-based AR is that many studies indicate no added communication value with video (for reviews see Sellen 1995; Whittaker \& O'Conaill, 1997). Chapanis (1988), for example, measured the time for pairs of people to solve problems under varying types of communication constraints, such as handwriting only, voice only, voice and video, and "communication rich" (problem solvers in same room). One problem was assembly of a cart where one person had the materials and another person had the instructions. Best performance was achieved when subject pairs were in the same room; when in separate rooms, video of a person assembling the cart did not help the pair solve the assembly problem any faster than other pairs who had only voice communication. However, in every case where voice communication was absent, performance slowed dramatically. The paradox in findings like these is that while a substantial literature on gestures, expressions, and postures ("body language") documents human capabilities for non-verbal communication, the absence of these visual signs appears to do little harm to communication.

Nardi and her co-workers (1997), in the work mentioned earlier, explain the paradox above as a case where the usual imagery in video-mediated communication is merely "talking heads" video showing the face or upper body of participants, rather than video conveying technical detail. That is, "talking heads" video is an attempt to provide telepresence, rather than an effort to enhance task performance. Nardi et al. present the case for "video-asdata, "where it is essentially impossible to convey the nature of a situation or work object without motion imagery. The setting studied was a neurosurgery operating room. During neurosurgery, neurophysiologists monitor a patient's neurophysiological responses and feed information back to the neurosurgeon and anesthesiologist if they suspect a problem. In the Nardi et al. study, multiple cameras allowed neurophysiologists to observe, from outside the $O R$, the surgical field, instrument data, and human activity in the OR. Video in this case provided more information to neurophysiologists than would have been available to them inside the OR. For example, without a camera, the surgical field--the area of the brain under surgery-would be visible only to the surgeon; all others would have a diminished view. Thus, neurophysiologists' ability to monitor and interpret patients' condition was enhanced, leading to remote monitoring of more than a single OR. With AR, a camera view or direct view of the real world is data, much like the "video-as-data" defined by Nardi et al. and, of course, is not limited to views of talking heads. The communication concept is actually a form of media that presents an already rich data source (the real world view) enhanced with additional information. Therefore, it may be that the value of video imagery is uncertain in a video conference mode, but clear when imagery is the data that really matters.

Realism in Graphic Additions to Real World Scenes

A related issue that affects both video-based and directview $A R$ is whether greater realism in pictorial material leads to more effective instruction. A number of studies indicate that there is no automatic advantage to elaborate artwork or photorealism in instructional material (Spencer, 1988; see Swezey \& Llaneras, 1997, for brief review). In one study, Schmidt and Kysor (1987) found that airline passenger safety cards were easier to understand when illustrated with simple drawings rather than with photographs. Line art is often more effective than highly detailed renderings for communicating technical facts, apparently because line art conveys nothing extra--just the minimum needed for understanding (Dwyer, 1967). The question presented to AR is that if the technology seeks to exploit real or camera views of the world by adding instructional material to them, wouldn't this combination present too much detail and actually inhibit technical communication? Although little research has appeared to investigate this question, we believe the answer will be no: it is the role of annotations and other graphic enhancements in AR to direct attention away from unnecessary detail and toward truly relevant parts of a scene. In a recent study in our labs, we presented subjects with a video record of an aircraft wing slat section; the slat had several geometric shapes painted on it. Some subjects saw just the slat section, and others saw the same video with several "neutral" annotations; that is, annotations without meaningful content but with leader lines connected to the geometric shapes on 
the slat. After showing the video, we asked subjects about the shapes painted on the slat; such as "How many vertical bars were present?" and "Was the red bar the second, third, or fourth bar up from the bottom?" In only three of 10 questions did the presence of annotations appear to divert attention away from the geometric shapes, an outcome consistent with the idea that annotations do not necessarily clutter a visual scene.

\section{Integrating Cognittive Tasks to Support Communication}

Augmented reality has been seen as an aid or at least a complement to human cognitive processes on several levels (Neumann \& Majoros, 1998). For example, comprehension in aviation-related communication is often dependent on the sender and receiver each having a great amount of knowledge about relevant topics before a communication episode begins. When such background or contextual knowledge is missing, comprehension is more difficult or impossible. Sometimes, this problem can be overcome if time is available to search for and retrieve the essential missing information. So in concept, if AR can present relevant information superimposed over views of world objects, then the search for and retrieval of information can be integrated with a user's communication or problemsolving task.

It may seem obvious that eliminating the search for information would benefit a task, but it is easy to overlook the impact of informational activities on workpiece performance. For example, "aircraft maintenance" evokes images of repair actions on actual hardware, but an airline spokesman reported that $\mathbf{4 5}$ percent of every technician's shift is actually spent on finding and reading procedural and related information (Ott, 1995). Nevertheless, simple observation tells us that tasks involve different activities, and from a cognitive standpoint, the skills and abilities invoked for these two requirements-information-related and the actual, hands-on solution to a problem--can be very different. Towne (1985) measured the time for two types of behavior in equipment fault isolation tasks: time for actual manipulation of devices and instruments (manual time), and time not engaged with devices or instruments (cognitive time). He found that cognitive time accounted for about 50 percent of total task time. Therefore, we can conclude that if cognitive activities had been reduced for the fault isolation technicians, their total task time would have been lowered. This is just the sort of benefit envisioned for $A R$ in manufacturing and maintenance tasks.

AR also uses views of world objects to convey meaning, possibly aiding recall and learning. Each association of a virtual object with a workpiece feature is the basis for a link in memory that might not otherwise exist. These links together (e.g., an array of callouts in a workpiece scene) may form a framework like that created when subjects use a classic mnemonic technique, called the method of loci, to remember a lists of items. With this method, a subject associates items to be remembered with invented places or landmarks on an imaginary path (Yates, 1984). During recall, the subject "mentally walks" on the path; and as he or she encounters the landmarks, the item associated with the landmark also appears, and is therefore available to working memory. A similar association of place and object is seen in air traffic control and the use of paper strips to represent aircraft. According to Mackay (unpublished draft), paper strips representing aircraft take advantage of multiple types of memory. Controllers "...mentally register the new traffic situation" when they touch and rearrange paper strips. This strong association between a paper strip (its presence, appearance, and location) and an aircraft's dynamic status (location, speed, heading) is actually an association of multiple concepts and dimensions supported by a physical object. In a similar manner, we believe the association between an annotation (with its appearance and content) and its perceived relation to a world object can convey meaning beyond what is contained in either the annotation or the world object alone.

\section{CURRENT COMMUNICATION MODELS}

\section{Relation of AR to Communication Models}

Perhaps the most important communication model in modern times is that of Shannon and Weaver (1949) which was based on the statistical concept of signal transmission. Noise impacting signal transmission in this model can degrade the fidelity of a signal, and can be compensated for by increased redundancy in a message. However, greater redundancy reduces the amount of information that can be transmitted in a given time over a medium with a given capacity. Transmitted information can be measured by the possibility of uncertainty reduction it produces, and the rate of transmission is a function of time and uncertainty reduction. In the Shannon and Weaver theoretical model, which became known as "information theory," information is not "meaning" and, in fact, is not related to particular facts and data but rather to numbers of possible choices about what might be transmitted and numbers of choices presented to a receiver. Information, "...relates, not so much to what you do say, as to what you could say" (Shannon \& Weaver, 1949, p. 100). A signal in its simplest form offers a present ("1") or absent ("0") status to a receiver: in either case, the choice for the receiver is between the signal or its opposite. A system having many possible states would present many options about what might be transmitted, and the receiver's uncertainty reduction would come through discrimination 
across numerous choices. Communication enabled by AR might be defined in a similar way: real world views can be annotated with virtually any content. The synthetic objects in composite scenes are under computer control, so text, links to Websites, access to artificially intelligent agents to assist the user, content tailored to the viewer, and many other options are all possible.

Despite the enormous influence of the Shannon and Weaver model, others have contended that information theory was developed to solve engineering problems, and was not intended or adequate to represent human communication. For example, Osgood (1954) described communication in a way that provided for both sending and receiving functions within one individual, and took into account the meaning of symbols. According to Osgood, individual humans function as both sources and destinations: they convey meaning-laden symbols to others and they decode their own encoded messages through a number of feedback mechanisms. In a classroom, for example, a lecturer observes student responses during a lecture, and may see signs of interest, boredom, approval, or disapproval among the listeners. These signs appear after the words of the lecturer, but become associated with the words just spoken and then, the new matrices of associations with words may affect subsequent expressions of the lecturer (e.g., he or she may change the topic).

Several areas of communication make it clear that meaning and associations have to be thoroughly considered in a model of human communication. Two of these are the role of perception in communication, and the effect of "automaticity" in our processing of symbols; AR as a communication medium is relevant to both.

Perception in communication. What people perceive in communication is affected by culture, motivation, attitude, and other factors (Severin \& Tankard, 1997). For example, people shown cultural images very briefly (e.g., a sports scene) will recall them according to games with which they are familiar rather than their true content, and people viewing ambiguous scenes will tend to see food-related items according to their level of hunger. AR suggests that certain perceptual characteristics in technical communication are actually subject to intervention by, or at least influence of, computer control. For example, the likelihood that an inspector will find defects in a sample (e.g. a line of rivets) during visual inspection is affected by the number of defects actually existing in the sample: a higher number of defects increases the chances that all will be found, a small number of defects decreases the chances that any will be found. Direct view AR coupled with natural feature recognition could be used to vary the information displayed at inspection sites to elevate a user's attention when the rate of defects is low, (e.g., different messages according to shades of color appearing on the edge of fasteners, or simple reminders to focus or pause).

Automaticity in information processing. An important model in communication is that our processing to extract meaning has context-driven (top-down) and feature-driven (bottom-up) characteristics (for review see Wickens \& Hollands, 2000, pp. 196-203). This effect applies to both written language and visual scenes. For example, letters in words are comprised of features such as straight or curved lines and angles. The features (in fact, a subset of them) uniquely define each of the 26 letters of the English alphabet, and are the basis for letter recognition. Thus, target letters (e.g., K) are easier to find among other letters with contrasting features (e.g., $O, S$ ) than among letters with similar features (e.g., N, X). So we are sensitive to features, but generally unaware of them during reading. Words too are perceived as units, and our interpretation of words is largely affected by surrounding words and sentences. The Stroop effect (Stroop, 1935) illustrates how strongly words are processed as meaningful wholes rather than as collections of letters: when color names are printed in conflicting ink colors ("red" printed with green ink), stating the color of the ink is surprisingly difficult.

This ability to recognize a letter while unaware of it features, and to read words as units are examples of automaticity in human information processing. Automaticity is a robust capability that transforms an effortful task into an effortless one--obviously a boon to technical communication. But to develop automatized processing can take many thousands of exposures to information. One promise of AR is to relieve people of the need for endless rehearsal before they benefit from effortless retrieval of information. In many concepts of communication with AR, the mere act of viewing an object in the world produces information relevant to the object. 


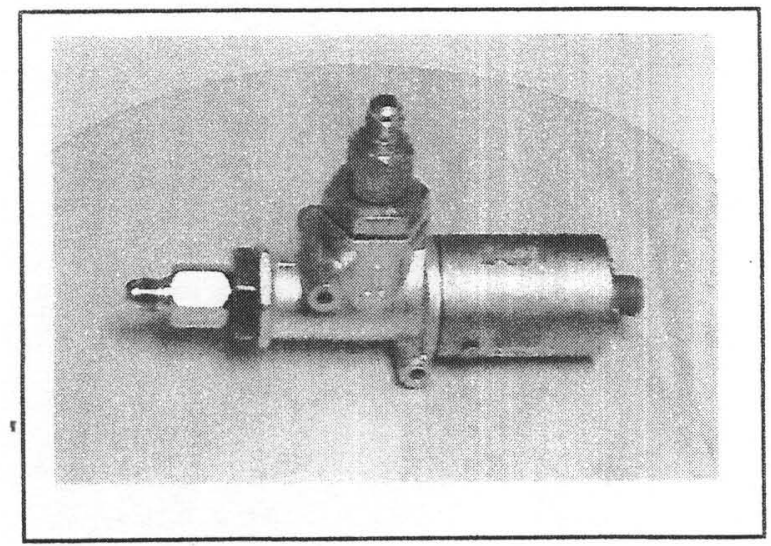

Figure 8. Workpiece for investigation of AR training modes: Space Shuttle nitrogen-regulating solenoid valve.

\section{TRENDS}

The variety of communication possibilities with $\mathrm{AR}$ suggests options intended to improve human performance. One fundamental question is whether some display modes are better suited than others to convey information. Subtleties exist here, and determining the best mode to exploit AR for communication is ongoing. For example, paper instruction has been optimized over many decades and can rival other modes having little or no development history (Jackson, Ealey-Sawyer, Lu, \& Jones, 2001), and Toth (1997) notes that image-based media may present extra demands for cognitive processing unless carefully planned. Joint research currently underway at Embry-Riddle Aeronautical University and the Boeing Company is investigating the potential of various training modes. The four modes under current investigation include a video training mode, a video-based interactive training mode, a video-based augmented reality training mode, and a printbased training mode. The goal of the research is to determine the effectiveness of the different modes while accounting for subject variables that may have hidden learning effects with composite imagery in previous studies. Control for some subjects' greater-than-normal or less-thannormal spatialization ability will be accomplished by pretesting with the Brief Visuospatial Memory Test Revised (Benedict, Schretten, Groninger, \& Dobraski, 1996) and statistically compensating for individual differences in this ability through analysis of covariance (ANCOVA). The literature in this area suggests that individuals who score high on this ability can link information to its location in the environment very efficiently.

A test of mechanical comprehension, a section from the Armed Services Vocational Assessment Battery (Hanser, 1997), will be also be administered as a matching variable to balance the strength of this ability in groups. The reason for this matching is that persons scoring high in this ability understand some elements of mechanical systems apart from training about specific devices. NASA officials at Kennedy Space Center have loaned a valve for use as a workpiece in this study (Figure 8).

\section{CONCLUSION}

Regarding information theory, one writer (Fantel, 1989) said: "What we have witnessed is more than a shift in technology. It is a shift in mentality. We have developed new ways of seeing and representing certain natural phenomena..." (p. 28). The same might be said of AR within a few years. The technology may extend or elaborate current models of communication or even require new models. The presentation of information in views of the world, the spatial registration of information so that it appears to be part of the world scene, and the aid provided to users through elimination of their need to search for information may define a new form of media. AR appears to have great potential for the enhancement of human performance through robust communication. The technology is adaptable to live and off-line conditions, for collaboration, or for cases where reduced human involvement is intended. Research is underway to determine the best methods and modes of use to capture the full advantages of the technology.t 
Anthony E. Majoros is a senior principal engineer scientist and technical fellow in crew systems technology in the Boeing Company. He specializes in the development of image-based communication technologies in the company's Phantom Works division, and provides crew systems design and development support to space and aviation programs.

Dennis A. Vincenzi is an assistant professor in the department of Human Factors and Systems at Embry-Riddle Aeronautical University (ERAU) in Daytona Beach, Florida. He was a post doctoral fellow at the Naval Air Warfare Center Training Systems Division (NAWCTSD) in Orlando, Florida for research in military aviation.

Sathya N. Gangadharan is a professor in the department of Engineering Technology at Embry-Riddle Aeronautical University (ERAU) in Daytona Beach, Florida. His areas of interest are in design and manufacturing of engineering systems specifically related to aerospace applications.

Paul R. Jackson is an advanced computer technologist in the Phantom Works division of the Boeing Company in Bellevue, WA. His undergraduate and graduate degrees are in electrical and computer engineering, respectively, and his current research includes augmented reality, advanced displays, and communication. 


\section{REFERENCES}

Bajura, M. \& Neumann, U. (1995). Dynamic registration correction in augmented reality systems. Proceedings of IEEE Virtual Reality Annual International Symposium (VRAIS), March 11-15, Research Triangle Park, NC.

Benedict, R.H.B., Schretten, D., Groninger, L., Dobraski, M. (1996). Revision of the Brief Visuospatial Memory Test: Studies of normal performance, reliability, and validity. Psychological Assessment, $\underline{8}$ (2), 145-153.

Billinghurst, M. \& Kato, H. (1999). Collaborative mixed reality. In Proceedings of the first international symposium on mixed reality (ISMR 99), Mixed reality: Merging real and virtual worlds. Berlin: Springer Verlag, 261-284.

Buxton, W. A. S. (1997). Living in angmented reality: Ubiquitous media and reactive environments. In K. E. Finn, A. J. Sellen, \& S. B. Wilbur (Eds.), Video-Mediated Communication, New Jersey: Lawrence Erlbaum, 363-384.

Caudell, T. P., \& Mizell, D. W. (1992). Augmented reality: An application of heads-up display technology to manual manufacturing processes. Proceedings of the Hawaii International Conference on System Sciences, $2.659-669$. Honolulu, Hawaii.

Chapanis, A. (1988). Interactive human communication. In I. Greif (Ed.) Computer-Supported Cooperative Work: A Book of Readings, 127-140. San Mateo, CA: Morgan Kaufmann.

Fantel, H. (1989). The advance was digital, and it's just a beginning. New York Times, Dec. 31, Sect. 2.

Curtis, D., Mizell, D., Gruenbaum, P., \& Janin, A. (1998). Several devils in the details: Making AR application work in the airplane factory. Program of the IEEE First International Workshop on Augmented Reality, San Francisco, CA.

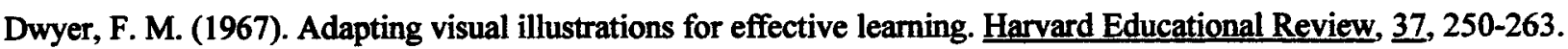

Feiner, S., MacIntyre, B., \& Seligmann, D. (1993). Knowledge-based augmented reality. Communications of the ACM, 36 (7), 53-62.

Grinberg, A. (1997). Seamless networks : Interoperating wireless and wireline networks. New York: McGraw-Hill.

Hanser, L.M. (1997). Criterion development in Project A. In R.F. Dillon (Ed.), Handbook on Testing, 256-273. Westport, CT: Greenwood Publishing Group.

Jackson, P., Ealey-Sawyer, J., Lu, I., \& Jones, S. (2001). Testing information delivery methods using augmented reality. Proceedings of the International Symposium on Augmented Reality (ISAR '01), 100-105.

Kanki, B,G. (2000). Aircraft maintenance research: The NASA program. In Proceedings of IEA/HFES 2000 Ergonomics for the New Millennium, San Diego, CA.

Majoros, A. E. and Neumann, U. (2001). Support of crew problem-solving and performance with augmented reality. Proceedings of Bioastronautics Investigators' Workshop, 25. Galveston, Texas,. (Expanded text available from first author.)

Mackay, W.E. (2000). Is paper safer? The role of paper flight strips in air traffic control. ACM/Transactions on Computer-Human Interaction, $\underline{6}(4), 311-340$. 
Nardi, B. A., Kuchinsky, A., Whittaker, S., Leichner, R., \& Schwarz, H. (1997). Video-as-data: Technical and social aspects of a collaborative multimedia application. In K. E. Finn, A. J. Sellen, \& S. B. Wilbur (Eds.), Video-Mediated Communication, 487-517. New Jersey: Lawrence Erlbaum.

Neumann, U., \& Cho, Y. (1996, July). A self-tracking augmented reality system. Proceedings of the ACM International Symposium on Virtual Reality and Applications, 109-115.

Neumann, U. \& Majoros, A. (1998). Cognitive, performance, and systems issues for augmented reality applications in manufacturing and maintenance. Proceedings of the IEEE Virtual Reality Annual International Symposium (VRAIS '98).

Osgood, C. E. (Ed.) (1954). Psycholinguistics: A survey of theory and research problems. Journal of Abnormal and Social Psychology, 49 (Oct.), Morton Prince Memorial Supplement.

Ott, J. (1995). Maintenance executives seek greater efficiency. Aviation Week and Space Technology 142 (20), May 15, 43-44.

Sellen, A. J. (1995). Remote conversations: The effects of mediating talk with technology. Human-Computer Interaction, 10(4), 401-444.

Severin, W. J. \& Tankard, J. W. (1997). Communication theories: Origins, methods, and uses in the mass media, ${ }^{\text {th }}$ Ed., 74-77. New York: Longman.

Schmidt. J. K., \& Kysor, K. P. (1987). Designing airline passenger safety cards. Proceedings of the $31^{\text {st }}$ Annual Meeting of the Human Factors Society, 51-55. Santa Monica, CA: Human Factors Society.

Shannon, C., and Weaver, W. (1949). The mathematical theory of communication. Urbana: University of Illinois Press.

Spencer, K. (1988). The psychology of educational technology and instructional media. London: Routledge.

Spohrer, J. C. (1999). Information in places. IBM Systems Journal, 38, (4), http://www.research.ibm.com/journal/ sj/384/spohrer.html.

Stroop, J. R. (1935). Studies of interference in spatial verbal reactions. Joumal of Experimental Psychology, 18, 643-662.

Swezey, R. W., and Llaneras, R. (1997). Models in training and instruction. In G. Salvendy (Ed.) Handbook of human factors and ergonomics, 514-577. New York: John Wiley \& Sons.

Towne, D. M. (1985). Cognitive workload in fault diagnosis (Report No. ONR-107, Contract No. N00014-80-C-0493 with Engineering Psychology Group, Office of Naval Research). Los Angeles, CA: Behavioral Technology Laboratories, University of Southern California.

Toth, L. S. (1997). Comparison of video demonstration versus written instruction in teaching a psychomotor task. Unpublished doctoral dissertation, University of Southern California.

Whittaker, S., and O'Conaill, B. (1997). The role of vision in face-to-face and mediated communication. In K. E. Finn, A. J. Sellen, \& S. B. Wilbur (Eds.), Video-Mediated Communication, 23-49. New Jersey: Lawrence Erlbaum.

Wickens, C. D. \& Hollands, J. G. (2000). Engineering psychology and human performance. $3^{\text {rd }}$ ed. Upper Saddle River, New Jersey: Prentice Hall.

Yates, F. A. (1984). The art of memory. London: Routledge and Kegan Paul. 
